\title{
Teaching
Methods
}

\section{Proposed Learning Outcomes for Four-year Horticulture Programs in the United States}

\author{
Marvin P. Pritts ${ }^{1}$ and Travis Park
}

\begin{abstract}
ADDITIONAL INDEX WORDs. curriculum development, learning goals, major
SuMMARY. Most institutions that offer a degree in horticulture have established a set of learning outcomes for the major or are in the process of doing so. Because horticulture programs are being subsumed into larger entities, and because there is no process for providing consistency of expectations for horticulture majors, a group of horticulture administrators from across the United States initiated an effort to develop a common set of learning outcomes that would be appropriate for any four-year horticulture program. The intent was to identify learning outcomes that could be made more specific for an institution's local conditions and capacities, or expanded to accommodate broader plant science-type majors. Five outcomes with specific goals were identified. An increasing level of higher-order thinking skills is associated with later learning outcomes. The outcomes are knowledge acquisition; knowledge integration; synthesis, creativity and problem-solving; communication; and demonstration of professionalism and proficiency. Adopting these learning outcomes can provide students with guidance in choice of major, faculty with a tool for curriculum development and program assessment, and employers with expectations for new horticulture graduates.
\end{abstract}

$\mathrm{L}$ earning outcomes are an expected component of most academic majors at U.S. universities [Association of Public and Land-grant Universities (APLU), 2009; U.S. Department of Education, 2006]. Students are expected to learn as a result of instruction based on a predetermined set of measurable outcomes (Krathwohl, 2002). Having documented outcomes creates expectations for students and aids in their choice of major (Burden and Byrd, 2003;

\footnotetext{
Department of Horticulture, Cornell University, Ithaca, NY 14886

The authors are grateful for the contributions and creativity of participants in the NCAC- 4 meeting who generated the learning outcomes, for those who shared learning outcomes from their institutions, and for those who commented on the poster. Thanks to Marcia Eames-Sheavly and Bryan Duff who provided helpful reviews and comments on the manuscript.

${ }^{1}$ Corresponding author. E-mail: mpp3@cornell.edu.
}

Krathwohl, 2002). They provide a roadmap for curriculum development and a framework for assessment of student learning (Association of American Colleges and Universities, 2010). Learning outcomes are usually developed for specific institutions based on available resources, current personnel, and the local context. However, students interested in a horticulture career must be broadly educated and prepared for a myriad of opportunities that exist throughout the country and world (APLU, 2009). In addition, employers increasingly indicate students are showing a dearth of skills in key areas, such as communication, and ability to engage and interact with others (VanDerZanden and Reinhart, 2009). Horticulture involves not only science, but also aesthetics, public education, business practices, and considerable human interaction. For this reason, learning outcomes developed for other scientific disciplines may not be sufficiently broad for a horticulture curriculum.

Learning outcomes should incorporate multiple levels of learning, ranging from lower- to higherorder thinking skills (Anderson and Krathwohl, 2001; Bloom et al., 1956). The original taxonomy of learning objectives includes knowledge, comprehension, application, analysis, synthesis, and evaluation (Bloom et al., 1956). Fink (2003) described a new "taxonomy of significant learning," emphasizing not just acquisition of knowledge, but also the search for meaning and coherence inherent in the human dimension, and the need to go beyond content mastery to include personal and social implications of what has been learned.

Learning outcomes, as defined by the Cornell University Center for Teaching Excellence (2012), are "measurable statements that articulate what students should know, be able to do, or value as a result of taking a course or completing a program." Learning outcomes are recommended for guiding overall educational programs, whereas leaving ample space for individualized decisions about more specific learning objectives. For example, a learning outcome might indicate students should understand plant physiology. Depending on individual courses, professors, or universities, a course may focus student learning on specific plants as models of physiology, such as tulip (Tulipa sp.), corn (Zea mays), or sequoia (Sequoia sp.).

More practically, horticulture departments across the country are disappearing as stand-alone units and are being merged and integrated with other plant-related departments. Many horticulturists fear that horticulture as a major and career track will be lost with organizational changes in academic institutions, and acknowledge the challenge of adapting the major in ways that are appealing to the current generation of students, many of whom are unfamiliar with the major, or associate it with low pay and physical labor. A discussion was started among academic leaders about the need to develop learning outcomes with wide applicability for four-year horticulture programs in the United States. Broadly accepted 
learning outcomes would help maintain a horticultural identity, lend credibility to programs, and ensure some common knowledge, skills, and understandings among horticulture grad-

\section{Methods}

At the 2011 American Society for Horticulture Science (ASHS) administrator's meeting in Waikoloa, $\mathrm{HI}$, a group of department chairs discussed the desirability of having a common set of learning outcomes for the horticulture major that all institutions could use. Many institutions had recently developed these, were in the process of doing so, or were expected to do so. In May 2012, representatives from horticulture departments across the country met in Ithaca, NY, as part of the annual North Central Administrator's Coordinating Committee (NCAC-4) for the purpose of developing a common set of learning outcomes that would be appropriate for any four-year horticulture major program. Twenty-nine department chairs and/or teaching uates or horticulture programs.

coordinators (Table 1 ) convened for $2 \mathrm{~d}$ in a facilitated discussion. Representatives were from every region of the country, from land-grant and nonland-grant institutions, and from both two- and four-year programs. Learning outcomes were solicited before the meeting from many institutions who have already established them, and these were made available to the group for consideration. Input was also solicited from members of the Certified Professional Horticulturist Board.

Since representatives came from departments having various configurations (with landscape architecture and design, crop science and agronomy, plant science, forestry), a first step was to agree on a definition of horticulture. The following working definition was used to define the parameters of the work. Horticulture: using plants to provide healthy whole foods, to build sustainably designed landscapes and to promote human health and well-being.

After extensive deliberation and discussion, outcomes were developed,

Table 1. List of contributors and associated institutions who convened in 2012 to develop proposed learning outcomes for a four-year horticulture program.

\begin{tabular}{ll}
\hline Representative & \multicolumn{1}{c}{ Institution } \\
\hline Auge, Robert & University of Tennessee, Knoxville \\
Azarenko, Anita & Oregon State University, Corvallis \\
Bailey, Douglas & University of Georgia, Athens \\
Baird, William & Michigan State University, East Lansing \\
Brown, Susan & Cornell University, Geneva, NY \\
Brown, Wyatt & California Polytechnic State University, San Luis Obispo \\
Collins, Michael & University of Missouri, Columbia \\
Compton, Michael & University of Wisconsin, Platte \\
Dole, John & North Carolina State University, Raleigh \\
Ferriss, Terry & University of Wisconsin, River Falls \\
Goldman, Irwin & University of Wisconsin, Madison \\
Hoover, Emily & University of Minnesota, St. Paul \\
Joly, Robert & Purdue University, West Lafayette, IN \\
Khalil, Aida & Morrisville State College, Morrisville, NY \\
Layton, Patricia & Clemson University, Clemson, SC \\
Marini, Richard & The Pennsylvania State University, University Park \\
Maynard, Brian & University of Rhode Island, Kingston \\
McAvoy, Richard & University of Connecticut, Storrs \\
Midden, Karen & Southern Illinois University, Carbondale \\
Nonnecke, Gail & Iowa State University, Ames \\
Paull, Robert & University of Hawaii, Manoa \\
Phillips, Jerry & Morehead State University, Morehead, KY \\
Pritts, Marvin & Cornell University, Ithaca, NY \\
Pulte, Andrew & University of Tennessee, Knoxville \\
Roper, Teryl & Utah State University, Logan \\
Sargent, Steven & University of Florida, Gainesville \\
Stanko, Carolyn & Niagara County Community College, Sanborn, NY \\
Williams, Kimberly & Kansas State University, Manhattan \\
\hline &
\end{tabular}

edited, and then shared with the group for comment. The edited version was then presented as a poster at the 2012 ASHS meetings in Miami, FL, where meeting participants were encouraged to make additional edits directly on the poster. These edits were incorporated into the final version of the learning outcomes resulting in a final product that received input from a wide and diverse group within the horticulture community.

\section{Results and discussion}

Learning outcomes were organized into five broad topics, each building on a foundation established by the previous ones (Table 2 ). The first outcome considers the acquisition, integration, and application of plant-science knowledge expected for horticulturists. This knowledge is often taught in formal classes and through books. The goals under this outcome are deliberately general so appropriate location-specific subgoals can be incorporated for various sorts of programs. Knowledge acquisition, remembering facts and definitions, and understanding principles are the bottom two levels of Bloom's taxonomy (Bloom et al., 1956), yet are fundamental for communicating concepts within the discipline.

The second outcome addresses the need to show competency within horticultural systems that are, by their nature, interdisciplinary. A competent horticulturist must be broadly knowledgeable, have the capacity to integrate knowledge across a range of disciplines (e.g., business, soils, pathology), and have the ability to actually perform physical tasks that require practice and training (e.g., grafting). This is a higher-order task than knowledge acquisition, and corresponds to the third level of Bloom's taxonomy where the application of knowledge and concepts must be demonstrated.

The third outcome encourages students to develop creative skills to solve problems and improve current systems. Such higher-order thinking builds on the previous two outcomes and moves the student to a level of competence on which a career can be based. The ability to solve problems ensures that a student truly comprehends how systems work and can intervene to make improvements or correct deficiencies. The highest level of learning according to Anderson and 
Table 2. Proposed learning outcomes for a four-year horticulture program in the United States.

Learning outcome 1: Acquire, integrate, and apply knowledge of plant science to managed systems

Goal 1. Use multiple sources, including current and older literature, to find, evaluate, organize, and manage information related to horticultural systems

Goal 2. Apply scientific methods to test hypotheses

Goal 3. Demonstrate competence with both laboratory and field-based technologies used in modern horticulture

Goal 4. Apply concepts of plant biology, systematics, ecology, and genetics to manage and improve plants and their products

Learning outcome 2: Demonstrate interdisciplinary knowledge and competency in managing horticultural systems

Goal 1. Assess soils, soil health, fertility, water, and site limitations

Goal 2. Recommend and use appropriate application methods, materials, and diagnostic skills for addressing soil constraints and irrigation, nutrient, stress, and pest management issues

Goal 3. Assess potential and evaluate realized interactions with the abiotic and biotic environment in which plants are grown

Goal 4. Recommend appropriate, effective and integrated approaches to produce and maintain high-quality food and ornamental crops

Goal 5. Apply principles of accounting, business law, labor, marketing, and personnel management to a horticultural business and contribute to developing the various components of a business plan

Learning outcome 3: Synthesize knowledge and use insight and creativity to better understand and improve plant systems

Goal 1 . Anticipate and recognize problems, identify causes of those problems, quantify potential impacts, analyze options, identify viable solutions to the problems, and evaluate actions and consequences of treatments and interventions

Goal 2. Develop, identify, and employ best management practices that lead to sustainable solutions and outcomes

Goal 3. Understand how global issues including climate change, energy use, water availability, and/or food safety impact the sustainability of horticultural systems locally, nationally, and globally

Learning outcome 4. Appreciate and communicate the diverse impacts of horticulture on people

Goal 1. Communicate effectively with various audiences using oral, written, and visual presentation skills, and contemporary networking/social media technologies

Goal 2. Describe the various ways plants impact human well-being (mental: psychological and restorative; physical: medicinal and physiological)

Goal 3. Describe and assess the influence of plants and their management on environmental sustainability and restoration

Goal 4. Quantify the economic importance of plants in managed ecosystems and the impact of horticultural crops in food systems

Goal 5. Describe the social, spiritual, and cultural importance of plants to historical and contemporary communities of people

Learning outcome 5. Demonstrate professionalism and proficiency in skills that relate to horticulture

Goal 1. Demonstrate leadership and the ability to collaborate and work in teams

Goal 2. Demonstrate a high level of personal and social responsibility

Goal 3. Develop a plan for life-long learning as it relates to career choice and professionalism

Goal 4. Develop thoughtful, clear, and consistent perspectives on ethical and moral issues related to horticulture

Goal 5. Demonstrate knowledge of a range of cultures, values, and political perspectives relevant for living in a global community Goal 6. Plan, engage, and learn from actions that demonstrate civic responsibility to community and society

Krathwohl (2001) is when a student can analyze, evaluate, and create a solution to a problem.

The fourth outcome sets an expectation that graduates will be able to communicate about more than just the science behind horticulture, but also about the social, spiritual, and cultural importance of plants. Students should be conversant about how plants contribute to sustainability and economic development. The audience for these communications should be much broader than the professors who teach the courses. Students should be able to communicate with audiences of varying technical expertise, and be able to relate their understandings to the larger society in which they live. Fink (2003) argued that this dimension to learning ought to complement Bloom's taxonomy.

Finally, horticulture graduates ought to have developed leadership skills, learned how to work in teams, and exhibit a high level of professionalism and personal responsibility. They need to appreciate diversity and be able to function outside of the dominant culture. They need to take principled positions on issues that have ethical implications, and be able to present their point of view intelligently and logically. Modern leadership training seeks to develop moral courage, emotional intelligence, and appreciation of diversity (Daft, 2005). Although a student in a four-year horticulture program is not likely to develop and practice all of the skills associated with leadership in the profession, programs should seek to provide opportunities to nurture students as they seek to acquire some of the more important leadership skills. Most importantly, leaders understand that learning does not end with the four-year degree, but continues throughout one's life (Daft, 2005).

Not all graduates will meet all of these outcomes, but every student can aspire to meet them. All horticulture programs, including the smallest of programs, should be able to provide opportunities to achieve within each outcome. And, because learning outcomes are a useful tool for evaluating program effectiveness (Middle States Commission on Higher Education, 2007), all horticulture programs 
could evaluate their teaching efforts with this framework of learning outcomes in mind.

We propose these learning outcomes (Table 2 ) be adopted by programs that have not yet established formal learning outcomes, and encourage those institutions with existing outcomes to consider if additional outcomes and goals are warranted, or if outcomes should be modified. Wide adoption of these learning outcomes, or similar ones, would help prospective students understand the field of horticulture, strengthen the value of a horticulture degree, and, ultimately, enhance the horticulture profession.

\section{Literature cited}

Anderson, L.W. and D.R. Krathwohl. 2001. A taxonomy for learning, teaching, and assessing: A revision of Bloom's taxonomy of educational objectives. Longman, New York, NY.
Association of American Colleges and Universities. 2010. Rising to the challenge: Meaningful assessment of student learning. 17 Feb. 2013. <http://www.eric. ed.gov/PDFS/ED519804.pdf>.

Association of Public and Land-grant Universities. 2009. Human capacity development: The road to global competitiveness and leadership in food, agriculture, natural resources, and related sciences (FANRRS). 17 Feb. 2013. <http://www. eric.ed.gov/PDFS/ED519804.pdf>.

Bloom, B.S., M.D. Engelhart, E.J. Furst, W.H. Hill, and D.R. Krathwohl. 1956. Taxonomy of educational objectives: The classification of educational goals. Longmans, New York, NY.

Burden, P.R. and D.M. Byrd. 2003. Methods of effective teaching. Pearson Education, New York, NY.

Cornell University Center for Teaching Excellence. 2012. Setting learning outcomes. 17 Feb. 2013. <http://www.cte. cornell.edu/teaching-ideas/designingyour-course/settting-learning-outcomes. html>.
Daft, R.L. 2005. The leadership experience. Thompson, Mason, $\mathrm{OH}$.

Fink, L.D. 2003. Creating significant learning experiences: An integrated approach to designing college courses. JosseyBass, Hoboken, NJ.

Krathwohl, D.R. 2002. A revision of Bloom's taxonomy: An overview. Theory Pract. 41:212-218.

Middle States Commission on Higher Education. 2007. Assessing student learning and institutional effectiveness: Understanding Middle States expectations. 17 Feb. 2013. <http://www. msche.org/publications/Assessment_ Expectations051222081842.pdf $>$.

U.S. Department of Education. 2006. A test of leadership: Charting the future of U.S. higher education. 17 Feb. 2013. <http://www2.ed.gov/about/bdscomm/ list/hiedfuture/reports/final-report.pdf>.

VanDerZanden, A.M. and M. Reinert. 2009. Employer attitudes and perceptions of job preparedness of recent Iowa State University horticulture graduates. HortTechnology 19:647-652. 